Bangladesh Journal of Anatomy July 2013, Vol. 11, No. 2 pp. 58-61

\title{
Study of Morphometric Analysis of Mandibular Foramen in Bangladeshi Dry Adult Human Mandible
}

\author{
Md. Mesbahul Hoque ${ }^{1}$, Shamim Ara², Shahanaz Begum ${ }^{3}$, \\ A.H.M. Mostafa Kamal ${ }^{4}$, Md. Abdul Momen ${ }^{5}$
}

\begin{abstract}
Context: Mandible is the lower jaw bone providing attachment of muscles of mastication and facial expression and provides pathway for inferior alveolar nerve and vessels. Adequate anaesthesia is a prerequisite of most of the dental procedures. Effective pain control in dentistry may be achieved by the local anaesthetic techniques; the most common procedures which are followed by the inferior alveolar nerve block. Therefore, identification of mandibular foramen is important for dental surgeons in nerve block and surgical procedures to avoid injury to neurovascular bundle. The aim of this study was to determine the position of the mandibular foramen from various anatomical landmarks.
\end{abstract}

Materials and Methods: A cross sectional analytical type of study was carried out in the department of Anatomy, Dhaka Medical College, Dhaka on one hundred and eighty five (185) dry adult human mandibles of unknown sex. Position of mandibular foramen was determined using the distance of the mandibular foramen to (a) the anterior border of the ramus (b) the posterior border of the ramus (c) the mandibular notch (d) the head of the mandible (e) the posterior edge of third molar socket and (f) the symphysis menti which were measured with the help of digital sliding calipers.

Results: The mandibular foramen was at the same distance from each landmark on both sides demonstrating symmetry. There was no significant difference in the values on the right and left sides of the mandibles.

Conclusion: Anatomical knowledge of this study might be useful in certain surgical procedure.

Key words: Mandibular foramen, inferior alveolar nerve, morphometry.

\section{Introduction}

The mandibular foramen (MF) is located above the center on the medial surface of the ramus. The mandibular canal starts at the MF and descends obliquely forward in the ramus and later in the body of mandible containing the inferior alveolar neurovascular bundle. ${ }^{1}$

The most frequent technique failure in anaesthesia of the inferior alveolar nerve lies in the in appropriate

1. Assistant Professor, Department of Anatomy, Satkhira Medical College, Satkhira.

2. Professor and Head, Department of Anatomy, Dhaka Medical College, Dhaka.

3. Professor and Head, Department of Anatomy, National Institute of Cardiovascular Diseases, Sher-E-Bangla Nagar, Dhaka-7

4. Assistant Professor, Department of Anatomy, Dhaka Medical College, Dhaka.

5. Assistant Professor, Department of Biochemistry, Ad-Din women's Medical College, Dhaka.

Correspondence: Dr. Md. Mesbahul Hoque setting of the needle, due to the inaccurate location of mandibular foramen ${ }^{2}$. The risk of undesirable mandibular fractures might decrease when the mandibular foramen is taken as anatomic repairs in osteotomies performed for orthognathic purposes $^{3}$. Sometimes, researchers do not come to an agreement as to its position in the anteroposterior direction ${ }^{4}$ and as to the occlusal plane ${ }^{5}$. A few studies have demonstrated that mandibular foramen maintains its location after skeleton maturation, even if the mandibular ramus suffers morphological alteration associated with tooth losses ${ }^{5,6}$.

Despite the significance of MF, little attention has been given to the study of the morphometry, location of foramen and associated anatomical characteristics in Bangladesh; hence this study has been conducted to investigate the location of MF 
with respect to the surgically encountered anatomical landmarks.

\section{Materials and Methods}

One hundred eighty five dried adult human mandibles with complete dentition and intact alveolar margin of unknown sex collected from the Department of Anatomy of Dhaka Medical College, Sir Salimullah Medical College and Shaheed Suhrawardy Medical College, Dhaka were used for this study. Position of mandibular foramen was determined using the distances of the mandibular foramen to (a) the anterior border of the ramus (b) the posterior border of the ramus (c) the mandibular notch (d) the head of the mandible (e) the posterior edge of third molar socket and (f) the mid-point on symphysis menti which were measured with the help of digital slide calipers. The distances from the MF to various landmarks were calculated as a mean of two measurements recorded independently by two peoples. Measurements were recorded to the nearest millimeter.
A comparison of the mean values between sides was performed using the paired 't'-test, $p$-value d" 0.05 was considered statistically significant.

\section{Results7}

The mean and standard deviation values of various parameters are shown in table-I. It was found that there was no significant difference in the values on the right and left sides except the distance between head of the mandible and mandibular foramen which was statistically significant $\left(<0.05^{*}\right)$. The distances (mean \pm SD) from MF to anterior border of ramus was $16.34 \pm 1.97 \mathrm{~mm}$ and $16.27 \pm 1.91 \mathrm{~mm}$, to posterior border of ramus was $14.14 \pm 2.36 \mathrm{~mm}$ and $14.04 \pm 2.32 \mathrm{~mm}$, to the mandibular notch was $22.29 \pm 3.43 \mathrm{~mm}$ and $22.18 \pm 3.32 \mathrm{~mm}$, to the head of the mandible was $40.76 \pm 4.71 \mathrm{~mm}$ and $40.26 \pm 5.00 \mathrm{~mm}$, to the third molar socket was $16.70 \pm 2.18 \mathrm{~mm}$ and $16.72 \pm 2.16$ $\mathrm{mm}$, to the symphysis menti was $71.46 \pm 4.05 \mathrm{~mm}$ and $71.00 \pm 4.60 \mathrm{~mm}$ on right and left side respectively.

Table-I

Distances (in $\mathrm{mm}$ ) from the mandibular foramen to various landmarks of the mandible

\begin{tabular}{lccc}
\hline Landmark & $\begin{array}{c}\text { Right side } \\
\text { Mean } \pm \text { SD }\end{array}$ & $\begin{array}{c}\text { Left side } \\
\text { Mean } \pm \text { SD }\end{array}$ & P value \\
\hline Anterior border of ramus & $16.34 \pm 1.97$ & $16.27 \pm 1.91$ & $>0.10^{\text {ns }}$ \\
& $(10.95-20.82)$ & $(10.69-20.61)$ & \\
Posterior border of ramus & $14.14 \pm 2.36$ & $14.04 \pm 2.32$ & $>0.50^{\text {ns }}$ \\
& $(9.10-17.98)$ & $(9.01-17.98)$ & \\
Mandibular notch & $22.29 \pm 3.43$ & $22.18 \pm 3.32$ & $>0.10^{\text {ns }}$ \\
Head of the mandible & $(16.80-31.38)$ & $(17.00-29.98)$ & \\
& $40.76 \pm 4.71$ & $40.26 \pm 5.00$ & $<0.05^{*}$ \\
Third molar socket & $(18.78-48.67)$ & $(17.98-48.75)$ & \\
& $16.70 \pm 2.18$ & $16.72 \pm 2.16$ & $>0.50^{\text {ns }}$ \\
Symphysis menti & $(12.12-23.40)$ & $(12.12-22.66)$ & \\
& $71.46 \pm 4.05$ & $71.00 \pm 4.60$ & $>0.10^{\text {ns }}$ \\
\hline
\end{tabular}

Comparison between right and left side done by paired Student's 't'test, ns= not significant, *= significant. 


\section{Discussion}

The mean $( \pm S D)$ distance between anterior border of mandibular ramus and mandibular foramen was $16.34 \pm 1.97 \mathrm{~mm}$ and $16.27 \pm 1.91 \mathrm{~mm}$ on right and left side respectively. This finding of the present study was consistent with Keros et al. ${ }^{7}$, Jerolimov et al. ${ }^{8}$, Oguz and Bozkir ${ }^{9}$ and Kilarkaje et $a^{11}$.

The mean $( \pm S D)$ distance between posterior border of mandibular ramus and mandibular foramen was $14.14 \pm 2.36 \mathrm{~mm}$ and $14.04 \pm 2.32 \mathrm{~mm}$ on right and left side respectively. This finding of the present study was similar to Nicholson ${ }^{12}$, Keros et al. ${ }^{7}$, Jerolimov et al. ${ }^{8}$, Oguz and Bozkir ${ }^{9}$ and Ennes and Medeiros ${ }^{10}$.

In the present study, the mean ( $\pm S D$ ) distance between mandibular notch and mandibular foramen was $22.29 \pm 3.43 \mathrm{~mm}$ and $22.18 \pm 3.32 \mathrm{~mm}$ on right and left side respectively. The present finding was consistent with Oguz and Bozkir ${ }^{9}$ and Kilarkaje et al. ${ }^{11}$ but differed from Ennes and Medeiros ${ }^{10}$ and Jerolimov et $\mathrm{al}^{8}$, where this distance was 25.19 $( \pm 4.25) \mathrm{mm}$ on both sides.

The highest mean $( \pm S D)$ distance between mandibular head and mandibular foramen was $40.76 \pm 4.71 \mathrm{~mm}$ of the total mandibles. This finding of the present study was consistent with Keros et al. ${ }^{7}$, Jerolimov et al. ${ }^{8}$ and Kilarkaje et al. ${ }^{11}$

The mean $( \pm S D)$ distance between posterior edge of $3^{\text {rd }}$ molar socket and mandibular foramen on right side was $16.70 \pm 2.18 \mathrm{~mm}$ and $16.72 \pm 2.16 \mathrm{~mm}$ on left side. According to Kilarkaje et al. ${ }^{11}$ this distance was $20.6 \mathrm{~mm}$ on right side and $20.7 \mathrm{~mm}$ on left side.

In the present study, the mean ( $\pm S D$ ) distance between symphysis menti and mandibular foramen on right side was $71.46 \pm 4.05 \mathrm{~mm}$ and $71.00 \pm 4.60$ $\mathrm{mm}$ on left side which was consistent with Kilarkaje et al. ${ }^{11}$

\section{Conclusion}

It was found in this study that the MF was positioned at a mean distance of $16.34 \pm 1.97 \mathrm{~mm}$ from the anterior border of ramus. The MF was at the same distance from each landmark on both sides demonstrating symmetry. This study provides statistical data to locate the MF, which maintains bilateral symmetry. These data may be of great help to locate the MF during surgery. They may also be useful in reconstructive surgery and anthropological assessments.

\section{References}

1. Beale TJ, Robinson PD. Infratemporal and Pterygopalatine fossae and Temporomandibular joint. In: Standring s, Boreley NR, Healy JC, Collins P, Johnson D, Crossman AR, et al. eds. Gray's Anatomy: The anatomic basis of clinical practice. 40th ed. UK: Elsevier Churchill Livingstone 2008. 530-33.

2. Hetson G, Share J, Frommer J, Kronman JH. Statistical evaluation of the position of the mandibular foramen. Oral Surg. Oral med. Oral pathol. 1988; 65(1): 4-32.

3. Quevedo Rojas LA. Osteotomia sagital de rama mandibular. Rev. esp. cirug. Oral y Maxilofac 2004; 26(1): 14-21.

4. Keros NJ, Panduric J, Buntak KD. Some anatomical and anthopological measures of mandibular ramus in our population. Coll. Antropol. 1997; 21(1):203-10.

5. Afsar A, Haas DA, Rossouw PE, Wood RE. Radiographic localization of mandibular anesthesia landmarks. Oral Surg. Oral Med. Oral Pathol. Oral Radiol. Endod. 1998; 86(2):234-41.

6. Carvalho PL, Pocobello MC, Reis SSP. Contribuiçäo ao estudo da posiçäo do forame mandibular nas radiografias panorâmicas. Arq. Odontol. 2003; 39(1):45-52.

7. Keros NJ, Bagi C, Muftic O, Vinter I. Position of mandibular foramen. Coll. Antropol. 1991; 15: 153.

8. Jerolimov V, Kobler P, Keros J, Stanicic T, Bagic I. Assessment of position of foramen 
mandibulae in recent adult population. Coll. Antropol. 1998; 22(1): 169-77.

9. Oguz O, Bozkir MG. Evaluation of the location of the mandibular and mental foramina in dry, young, adult human male, dentulous mandibles. West Indian Med. J 2002; 51(1): 6-14.

10. Ennes JP, Medeiros RM. Localization of Mandibular foramen and clinical Implications. Int. J. Morphol. 2009; 27(4):1305-11.
11. Kilarkaje N, Nayak SR, Narayan P, Prabhu LV. The location of the mandibular foramen maintains absolute bilateral symmetry in mandibles of different age-groups. Hong Kong Dental Journal 2005; 2: 35-37.

12. Nicholson ML. A study of the mandibular foramen in the adult human mandible. Anat. Rec. 1985; 212(1):110-12. 